\title{
Beyond voluntary consent: Hans Jonas on the moral requirements of human experimentation
}

\author{
Charles Fethe Kean College, New fersey, USA
}

\section{Author's abstract}

In his essay, Philosophical Reflections on Experimenting with Human Subjects, Hans fonas contends that except in cases of widespread medical emergencies, people do not have a moral or social obligation to volunteer to be subjects in medical experiments. He further argues that any appeal for volunteer subjects in medical experiments should whenever possible give priority to those who can identify with the project and offer a strong sense of commitment to its goals. The first of these claims is given support against some recent criticisms, but argument is offered to show that the second claim not only does little to enhance the stature of the standard requirement of free and informed consent but may even weaken the moral validity of the consent.

\section{Introduction}

The history of medical research in the twentieth century provides abundant evidence to show how easy it is to exploit individuals, especially the sick, the weak and the vulnerable, when the only moral guide for science is a naive utilitarian dedication to 'the greatest good for the greatest number'. So the central problem we face in formulating an ethical policy for research on human beings is to find some way to safeguard experimental subjects without stopping the progress of scientific exploration. A common solution to this problem lies in developing guidelines which stress individual rights and the need for free and informed consent; but one of the most widely reproduced philosophical essays on human experimentation takes a very different, and ethically more rigorous, approach to protecting the research subject. Now generally recognised as a classic in the field of medical ethics, Hans Jonas's essay, Philosophical Reflections on Experimenting with Human Subjects devotes little attention to the importance of rights or the need to balance individual risk with social good. (1). Instead, Jonas advocates that

\section{Key words}

Medical experimentation; human subjects; Hans Jonas. experimentation be based on a concept of consent which has its source in a quasi-religious sense of the holy and goes well beyond the requirement that a morally valid consent must be informed and uncoerced.

Jonas's essay gives us a helpful means for assessing some of the commonly accepted assumptions which now govern the use of consent in protecting experimental subjects, and in this paper I should like to examine two claims he makes in his defence of this morally 'higher' or at least more demanding concept of consent. The first is his claim that consenting to be an experimental subject falls beyond the bounds of our normal social and moral obligations; and the second is his claim that a morally valid consent must be not only uncoerced and informed but based on a strong sense of personal commitment to the experiment. These two claims by no means exhaust Jonas's rich description of a morally valid consent, but they are central to his argument and provide a good insight into his basic ethical philosophy.

\section{Consent and moral obligation}

Jonas introduces his analysis of consent by reflecting on the conditions under which society would be justified in soliciting subjects for medical experimentation. He recognises that widespread medical disasters, such as an unchecked plague or a sudden drop in birthrate, might justify the use of extreme measures to support the requirements for human experimentation; but since events such as these are fortunately rare, he focuses his analysis on the solicitation or recruitment procedures which should be used to obtain volunteer subjects under normal circumstances. What kinds of argument, what sorts of appeal are medical researchers justified in making to potential subjects when their goal is not to avoid a pandemic medical emergency but to advance the general cause of health and continue the everyday struggle against disease, illness and infirmity?

In the case of therapeutic experiments, where the experimental subject is a patient who might gain direct health benefits from the knowledge obtained through the experiment, the appeal for volunteers can be properly made on the basis of the subject's 
self-interest. But what of those very common experiments where the appeal must be made to healthy people who would derive no medical benefit from their participation, as would normally be the case, for example, in testing new vaccines? It is the appeal for subjects in these non-therapeutic experiments which most clearly displays the moral problems of experimental recruitment; for some researchers have attempted to enhance the appeal by claiming that people have a general social duty to volunteer, at least when the experiments pose minimal risk or threat of harm. Volunteering to be an experimental subject, in this view, is simply a way of fulfilling our obligations and paying a debt we owe to present and future generations. Jonas strongly objects to this moral claim: there is, he argues, no general social obligation or moral duty to volunteer to be an experimental subject.

Jonas's objection to the attempt to bring participation in experiments within the bounds of social and moral obligation is based on his conviction that all experimentation, even when it is non-harmful, treats the experimental subject as a passive 'token' or sample and thereby threatens the dignity of the person as a unique individual. Since respect for the dignity of the individual is an essential element in our moral code, it would be wrong to include within the terms of the social contract an obligation to sacrifice one's status as an active, unique and selfdetermining individual. Jonas reinforces this argument by noting that any attempt to present the act of volunteering as a social duty would certainly be a way to pressure people and so would endanger the moral validity of the act of consent. A truly moral consent - what Jonas calls 'authentic' consent - must lie beyond the call of duty. It represents a higher ethical calling. 'The ethical dimension,' says Jonas, 'far exceeds that of the moral law and reaches into the sublime solitude of dedication and ultimate commitment, away from all reckoning and rule - in short, into the sphere of the holy. From there alone can the offer of self-sacrifice genuinely spring ...' (2). Whether people will make such a commitment, says Jonas, is a matter that must be left to fortuitous 'grace'.

In a critique of Jonas's views on the moral duty to be a subject of a medical experiment, Arthur Shafer expresses a common objection in claiming that 'Jonas's position would require the virtual cessation of medical research on human beings' (3). But what grounds are there for expecting such a dire consequence? Shafer is led to this judgement because he interprets Jonas as holding that 'the submission of human subjects to research which is hazardous should not be sought or accepted unless the community is faced with the sort of "clear and present danger" which a raging epidemic poses' (3). I believe this is a mistaken interpretation of Jonas's position. Jonas does not deny that society can accept volunteers in non-emergency situations; had he held such a view he would not have devoted so much attention to reformulating the moral requirements of consent. Nor does Jonas deny that society can solicit volunteers. He argues only that such solicitation must not be bolstered with the claim that heeding the call is a civic or moral obligation. It may well be true that a society which follows Jonas's moral philosophy would have far fewer volunteers for non-therapeutic medical experiments than would a society which uses coercion, pressure or the appeal to social duty, but the call for subjects would still be made and I see no reason to think that adopting Jonas's position would bring non-therapeutic medical experimentation to a halt.

To attack Jonas's position effectively, one must look not at the obstacles it might pose for obtaining experimental subjects but at the validity of Jonas's claim that volunteering for medical experimentation is not part of the normal repertoire of moral obligations and social duties. In a later part of his article, Shafer attempts to refute or at least weaken Jonas's contention by arguing that it is morally eccentric. 'It is now widely, though not universally, accepted that we have an obligation as a society to provide adequate medical care for everyone,' says Shafer. 'This obligation would seem to entail that society promote the development of effective treatments. To forego medical experimentation would be to deprive ourselves of the benefits of new remedies; and not only ourselves, but future generations as well' (4).

I would agree with Shafer that people do have a moral obligation to support a system of health care, but it is not clear to me how one can forge a link between this obligation and a duty to volunteer as an experimental subject. The social obligation to provide adequate health care certainly would justify society in demanding contributions to support the system of health care, and so I am sure that most people would agree that government is within its rights when it imposes taxes to pay for hospitals, nursing homes, medical fees and the like. But I doubt that people would believe that a medical conscription to obtain an army of experimental subjects or even the attempt to apply moral pressure to obtain such subjects would be justified. 'Tax me but don't test me,' seems a perfectly sensible view. Taxation, after all, represents a standard procedure for exacting social obligations; but introducing a social duty to volunteer for medical experiments presents a claim for a different kind of sacrifice: here my body rather than my fungible resources is being used, and so the sacrifice is more personal, deeper within that sphere which we normally like to think of as protected from social encroachment. Furthermore, while the taxation requirement attempts to be equitable, making greater demands on those who have greater wealth, the moral basis for determining who should carry the greatest weight of the duty to be a medical volunteer is much less clear: who should be exempt from the call - the elderly, the 
sick, the poor? It may be possible to deduce a general moral obligation to volunteer for medical experiments from the social duty to support an adequate level of health care, but it will require more argument than Shafer or anyone else known to me has given it.

Jonas's claim that the act of volunteering for a medical experiment lies beyond the realm of social obligations is part of his general effort to portray the unique moral character of this action. Of equal importance in this project is his argument that the act of volunteering should whenever possible be based on the subject's 'identification' or sincere commitment to the experiment. I believe it is here, in his discussion of identification, that Jonas's essay faces its most serious philosophical objections.

\section{Identification and authentic consent}

Not all consents, not even all uncoerced and informed consents, are morally valid. To determine the moral quality of an act of consent we must look beyond the act itself and consider its motives and the role it plays in the life of the person who makes it. To Jonas, a truly moral or 'authentic' consent must be not only free and informed: it must also represent the subject's identification with the project he is consenting to. The following quotation is Jonas's description of the kind of identification needed to give full moral validity to the act of consent:

'The ruling principle in our considerations is that the "wrong" of reification can only be made "right" by such authentic identification with the cause that it is the subject's as well as the researcher's cause whereby his role in its service is not just permitted by him, but willed. That sovereign will of his which embraces the end as his own restores his personhood to the otherwise depersonalizing context. To be valid it must be autonomous and informed. The latter condition can, outside the research community, only be fulfilled by degrees; but the higher the degree of the understanding regarding the purpose and the technique, the more valid becomes the endorsement of the will. A margin of mere trust inevitably remains. Ultimately, the appeal for volunteers should seek this free and generous endorsement, the appropriation of the research purpose into the person's own scheme of ends. Thus, the appeal is in truth addressed to the one, mysterious, and sacred source of any such generosity of the will - "devotion," whose forms and objects of commitment are various and may invest different motivations in different individuals' (5).

It is, of course, rather difficult to recognise when a volunteer's choice is based on a devotion of this kind, and so Jonas offers us some suggestions on where it is likely to be found:
'The following, for instance, may be responsive to the "call" we are discussing: compassion with human suffering, zeal for humanity, reverence for the Golden Rule, enthusiasm for progress, homage to the cause of knowledge, even longing for sacrificial justification (do not call that "masochism", please). On all these, I say, it is defensible and right to draw when the research objective is worthy enough; and it is a prime duty of the research community (especially in view of what we called the "margin of trust") to see that this sacred source is never abused for frivolous ends' (5).

Requiring a commitment of this kind from research subjects would reduce the number of acceptable volunteers, but Jonas believes a reduction in resources is simply the price one must be willing to pay in order to ensure the moral validity of the act of consent. There are, however, other obstacles in the way of accepting the identification requirement, and I shall try to show that they pose a stronger threat to the moral basis of Jonas's recommendations.

\section{Moral problems with the identification requirement}

Jonas undoubtedly believes that the identification requirement enhances the moral stature of consent. The identification requirement would give validity only to consent based on the subject's own values and thus reduce the chances that the subject could be manipulated or pressured into agreement. But I believe the identification requirement would not seriously affect the possibility of manipulation nor would it guarantee that the consent is an expression of the individual's free choice.

A good example of the way in which identification can be put in the service of manipulation is Stanley Milgram's famous psychological experiment on obedience (6). In this experiment, Milgram set up a deceptive situation in which volunteer subjects believed they were inflicting electrical shocks on someone as part of an experiment to test how pain affects memorisation. In actual fact, no one was being given shocks, and the aim of Milgram's experiment was to see whether the volunteer subjects would continue to obey the instruction to give the shocks even when it appeared to them that someone was being seriously hurt by what they were doing. Milgram's experiment was strongly attacked because of its use of deception and because of the possible serious psychological damage that subjects might suffer later when they came to think about what they had done; but Milgram argued in his own defence that the experiment was justified because in postexperiment interviews a large number of the subjects expressed full support for the experiment, agreed that it should have been done, and even in some cases said that it was one of the most valuable experiences in their lives (7). 
Milgram's subjects undoubtedly identified with the experiment, but they were manipulated nonetheless. It might be thought that the Milgram experiment does not really pose a problem for Jonas's view since Jonas would insist that a consent expressing identification must also be free and fully informed. Since Milgram's experiment was based on deception, it would automatically be ruled out by Jonas as invalid. But this reply shows a failure to understand the significance of Milgram's experiment, for what Milgram has unwittingly demonstrated is how easy it is to get people to consent to an experiment and identify with its aims. If experimental subjects who are tricked into doing something that is considered morally wrong still commit themselves to the experiment and express strong support of it, how much easier will it be to elicit such identification when everything is on the up and up and the goals of the experiment are presented as worthy of pursuit.

I am not aware of any statistics on whether people who take part in experiments tend to support the experiments when they are over, but I would expect that the high degree of support that Milgram received would not be unusual, even when people enter the experiment for pay or just to have something to do. It is a fact of human nature that people want to find value in the activities they engage in; and when as in the case of a medical experiment, the activity is surrounded with the aura of science and the prospect for some kind of improvement for humanity, it is surely very easy to make the kind of identification and commitment which Jonas stresses as so morally important.

If the above argument is correct, then the identification requirement would probably not provide much more of a guarantee against manipulation than we already have with the basic requirement that the consent be free and informed. But I think if we consider some of the motives which often lie behind commitments to experiments, we can see even further objections to Jonas's belief that the identification requirement enhances the moral quality of consent.

There are many reasons why a person might commit him or her self to a medical experiment and identify with it, and not all of these reasons would support the moral stature of the commitment. Jonas recognises this, and in the passage quoted above, he offers a sample of the reasons that would make the commitment a morally acceptable one. Some of these, such as 'zeal for humanity' and 'sacrificial justification', are a bit difficult to understand, but the language suggests that a fairly strong commitment is needed. The moral problem I see here is that people who are guided by motives of this sort are not the kind of people who are best able to make the kind of commitment we normally would like to have.

Suppose, for example, we discover that one of our volunteer subjects is strongly committed to a medical experiment because members of his family have suffered from the disease which is the subject of the experiment. Does his commitment here have a moral quality to it? Those who follow a Kantian philosophy would certainly think not, for it may be that what we have here is not a moral commitment based on principle but an emotional drive. And even if we find this Kantian view too harsh, it still must be admitted that a person in this situation may not be in a good position to look at his choice objectively and determine whether this is actually a sensible choice to make. The kinds of motives which Jonas appeals to and would set up as the moral foundation of an authentic choice are quite powerful motives, easily associated with fanaticism; they may represent not a strong expression of self but fears, false hopes, even a sense of personal unworthiness and desire for selfsacrifice. I am not saying this would be true in all or even many cases, but the possibility of this occurrence indicates that the requirement of identification which Jonas imposes carries with it moral risks and cannot be accepted as something which will always enhance the moral character of the volunteer's choice.

\section{Conclusion}

Moral restrictions on who will be accepted as volunteers for human experimentation must always be designed to ensure the protection of the subject. Jonas's suggestion that a morally valid consent must be based on a strong sense of identification and commitment to the experiment does not appear to me to achieve this goal; for although this restriction would prohibit solicitation of those who are uncertain or hesitant to make a commitment, it would not protect those whose commitment is the result of morally dubious emotional states which drive people towards self-sacrifice. Sometimes we need to protect people from themselves. But I would agree with Jonas that however we define a morally valid consent to be an experimental subject, we must always recognise that this kind of act of volunteering, especially in non-therapeutic experiments, requires more than that the choice be free and uncoerced. I hesitate to follow Jonas in thinking of the act as 'holy' and a testimony to 'grace'; but it is surely beyond the realm of the normal call to duty, and any moral guidelines for human experimentation which failed to recognise its special moral stature would have to be judged inadequate.

Charles Fethe is Professor in the Department of Philosophy, Kean College, Union, New fersey, USA.

\section{References}

(1) Jonas H. Philosophical reflections on experimenting with human subjects. Daedalus 1969; 98: 219-247. My citations will be taken from the expanded version of 
this essay which appears in Jonas's book, Philosophical essays: from ancient creed to technological man. Chicago: University of Chicago Press, 1974: 105-131.

(2) See reference (1): 119.

(3) Shafer A. Experimentation with human subjects: a critique of the views of Hans Jonas. Fournal of medical ethics 1983: 9; 76.

(4) See reference (3): 77.

(5) See reference (3): 122.
(6) See Milgram, S. Obedience to authority: an experimental view. New York: Harper and Row, 1974.

(7) On page 199 of Obedience to authority, Milgram says: 'The central moral justification for allowing a procedure of the sort used in my experiment is that it is judged acceptable by those who have taken part in it. Moreover, it was the salience of this fact throughout that constituted the chief moral warrant for the continuation of the experiments.'

\section{News and notes}

\section{Imperial College Annual Intensive Ethics Course}

The course will be held from 13-17 September 1993 in London. Designed as an introduction to philosophical medical ethics for doctors, medical and nursing teachers, ethics committee members, medical administrators and medical lawyers, the course involves lecture/seminars and small and large group work.

The course is directed by Dr Raanan Gillon,
Editor of the Fournal of Medical Ethics and speakers will include British and international authorities in the field. Participant ratings over the last ten years have consistently given an overall rating of better than 9 out of 10 satisfaction.

For details write to Pamela Manser, Continuing Education Centre, Imperial College, London SW7 1NR. Telephone: 071-225 8667. 